\author{
Jurnal E-KOMTEK (Elektro-Komputer-Teknik) \\ Vol. 4, No. 2 (2020) pp. 184-190 \\ https://jurnal.politeknik-kebumen.ac.id/index.php/E-KOMTEK \\ p-ISSN : 2580-3719 e-ISSN : 2622-3066
}

\title{
Pengujian Kabin Sirkulasi Pendingin pada Trainer Simulator Air Conditioning Mobil
}

\author{
Hamid Nasrullah $^{1^{*}}$, Bahtiar Wilantara ${ }^{2}$, Parikhin ${ }^{3}$, Barlin Prastaji ${ }^{3}$ \\ 1,2,3,4Mesin Otomotif, Politeknik Dharma Patria, Indonesia, 54311 \\ *E-mail : hamid@politeknik-kebumen.ac.id \\ Doi : : https://doi.org/10.37339/e-komtek.v4i2.407
}

Diterbitkan oleh Politeknik Dharma Patria Kebumen

\section{Info Artikel}

Diterima :

14-12-2020

Diperbaiki :

17-12-2020

Disetujui :

$17-12-2020$

\begin{abstract}
ABSTRAK
Pengujian sirkulasi pada trainer simulator air conditioning mobil bertujuan untuk menguji media pembelajaran simulator sistem air conditioning mobil dengan perantara bahan plastik sebagai bilik kondisi ruangan tertutup pada praktikum mata kuliah sistem air conditioning mobil. Metode penelitian yang digunakan adalah metode penelitan deskriptif dan dokumentasi. Untuk memperkuat hasil penelitian yang memiliki relevansi yang erat dengan pokok permasalahan maka pengambilan data dengan cara observasi dan studi kepustakaan. Hasil pengujian pada trainer simulator air conditioning pada menit ke-20 yaitu: 1) kecepatan putaran blower tinggi suhu kabin rata-rata $17^{\circ} \mathrm{C}$, 2) Kecepatan blower sedang suhu kabin di bawah $17^{\circ} \mathrm{C}$, dan 3) Kecepatan blower rendah rata-rata suhu kabinnya $20^{\circ} \mathrm{C}$.

Kata kunci: Sirkulasi; Simulator; Air Conditioning; Mobil
\end{abstract}

\begin{abstract}
The circulation test on the car Air Conditioning simulator trainer aims to make it easier for students to test the car Air Conditioning system simulator with plastic as an intermediary for a closed room condition as well as a learning medium when doing prAir Conditioningticum on car Air Conditioning system courses. The research method used is experimental research methods and documentation. To strengthen research results that have a strong relevance to the subject matter, data collection is done by means of observation and literature study. The test results on the Air Conditioning simulator trainer in the high blower rotation speed, the cabin temperature averaged $17^{\circ} \mathrm{C}$. The low blower speed averages $20 \mathrm{C}$ of cabin temperature. The lowest temperature in the low blower speed is $18^{\circ} \mathrm{C}$ in 85 minutes. For medium and high blower speeds from 20 minutes the cabin temperature is below $17^{\circ} \mathrm{C}$.

Keywords: Circulation; Simulator; Air Conditioning; Car
\end{abstract}

Alamat Korespondensi : Jl. Letnan Jenderal Suprapto No.73 Kebumen, Jawa Tengah, Indonesia 55431 This work is licensed under a Creative Commons Attribution-NonCommercial 4.0 International License. 


\section{PENDAHULUAN}

Sirkulasi air conditioner lebih berfungsi sebagai pendingin pada ruangan mobil [1]. Air conditioning pada mobil merupakan suatu kebutuhan yang pokok pada mobil-mobil masa kini sebagai sarana untuk mencegah polusi udara masuk kedalam mobil [2]. Selain dari sisi pengaman pengendara dan penumapang lebih terjamin kenyamana karean pintu dan jendela harus ditutup dan dihidupkan. Air conditioning yang menggunakan siklus refrigerasi kompresi uap pada kendaraan dan kompresor digerakkan oleh mesin untuk menjalankan siklus kondensasi, ekspansi dan evaporasi [3]. Siklus AC dimulai dari proses kompresi kemudian kompresor menghisap refrigeran gas dari evaporator untuk ditekan [4]. Selanjutnya keluar dari kompresor refrigeran berwujud gas dengan tekanan tinggi masuk ke dalam kondensor untuk dilakukan kondensasi.

Permasalahan yang sering terjadi pada air conditioning yaitu kurangnya pengetahuan pengguna tentang kondisi baik dan buruknya tentang standar pendinginan air conditioning di dalam ruangan mobil. Hal tersebut terjadi dikarenakan kurangnya edukasi atau keingin tahuan pengguna mobil dalam mengetahui tentang kondisi pendinginan dan perawatan yang tepat untuk air conditioning.

Berdasarkan permasalahan tersebut diperlukan kompetensi yang dapat mendukung pengetahuan tentang pengujian dan dapat melakukan analisis troubel shooting pada air conditioning melalui media pembelajaran trainer simulator air conditioning mobil. Sehingga diharapkan memudahkan mahasiswa dalam melakukan pengujian pada simulator sistem air conditioning mobil serta sebagagai media pembelajaran pada saat melakukan praktikum mata kuliah sistem air conditioning mobil. Studi eksperimental dilakukan untuk mengetahui hasil pengujian pada penelitian yang akan dilakukan [5].

\section{MATERIAL DAN METODE}

\subsection{Material}

Komponen dan bahan yang dibutuhkan dalam proses pembuatan trainer simulator sistem Air Conditioning mobil antara lain [6] : Kompresor, kondensor, receiver dryer, expansion valve, evaporator, Batrai, besi holow, freon, kabel, akrilik, cat warna, roda, jepit buaya, Freon. Sedangkan Alat yang digunakan dalam pengujian sirkulasi pendingin pada trainer simulator sistem air conditioning mobil yaitu thermometer, pompa vakum, avometer dan manifold gauge. 
Mekanisme kerja air conditioning adalah mengatur sirkulasi udara dalam kabin dengan bahan plastik adalah adanya blower [7], kecepatan sirkulasi udara dapat diatur, sehingga udara yang bergerak memiliki kemampuan mengambil panas dengan maksimal.

Kemudian didalam merencanakan kerangka dan penempatan posisi komponenkomponen pada trainer simulator air conditioning mobil diperlukan perencanaan desain mendasar [8] yang disajikan pada Gambar 1 .

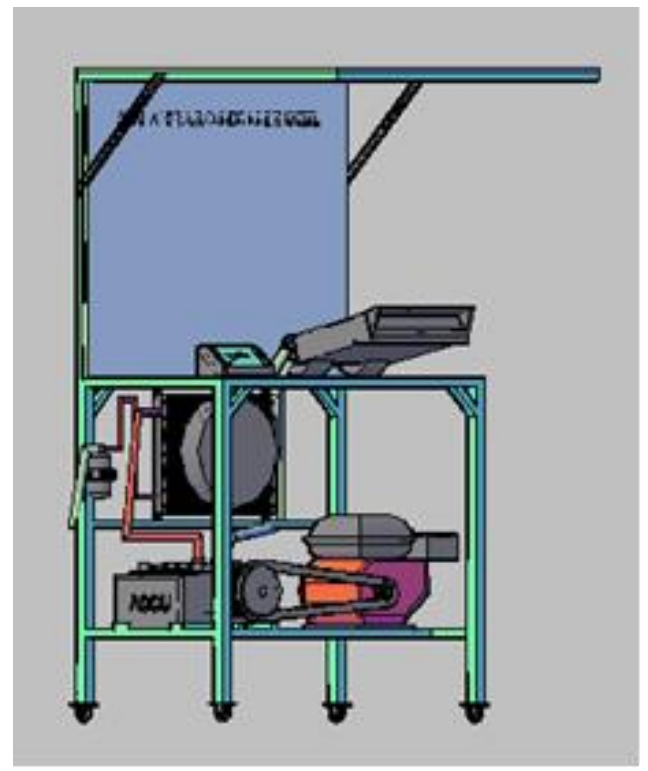

Gambar 1. Desain Perencanaan Kerangka dan Penempatan Posisi Komponen

Kemudian langkah selanjutnya yaitu desain sirkulasi pendingin pada trainer simulator Air Conditioning mobil sebagai media pembelajaran diperlukan perencanaan desain yang disajikan pada Gambar 2.

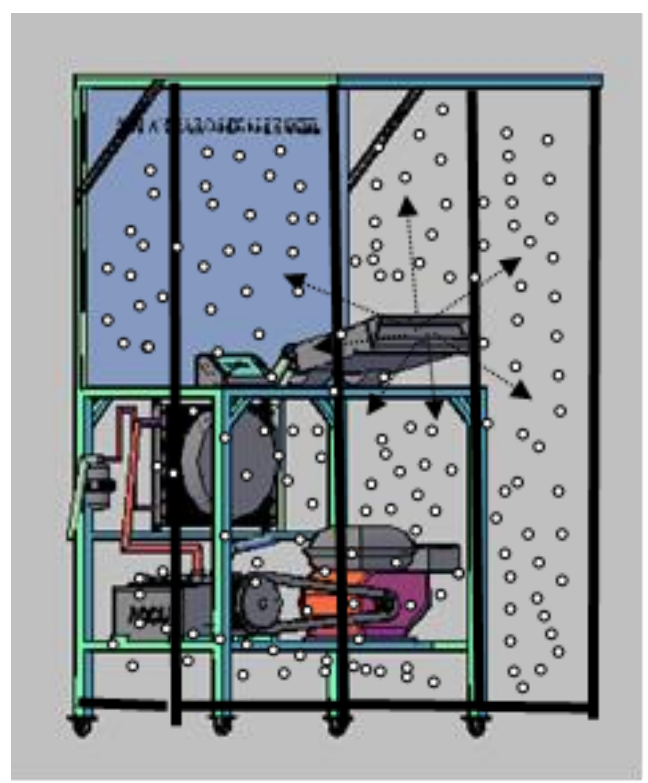

Gambar 2. Desain Sirkulasi Pendingin pada Trainer Simulator Air Conditioning 
Desain tersebut sebagai air conditioninguan untuk pembuatan Trainer Simulator Air Conditioning mobil sehingga sesuai dengan perencanaan dan hasil pengujian yang diinginkan.

\subsection{Metode}

Penelitian ini merupakan penelitian deskriptif yang bertujuan untuk mengetahui fenomena penyebaran udara dingin ke ruang kabin pada simulator air conditioning [9]. Langkah pelaksanaan proses penelitian pengujian sirkulasi pendingin menggunakan bahan plastik sebagai kabin pada simulator air conditioning mobil [8] disajikan pada Gambar 3.

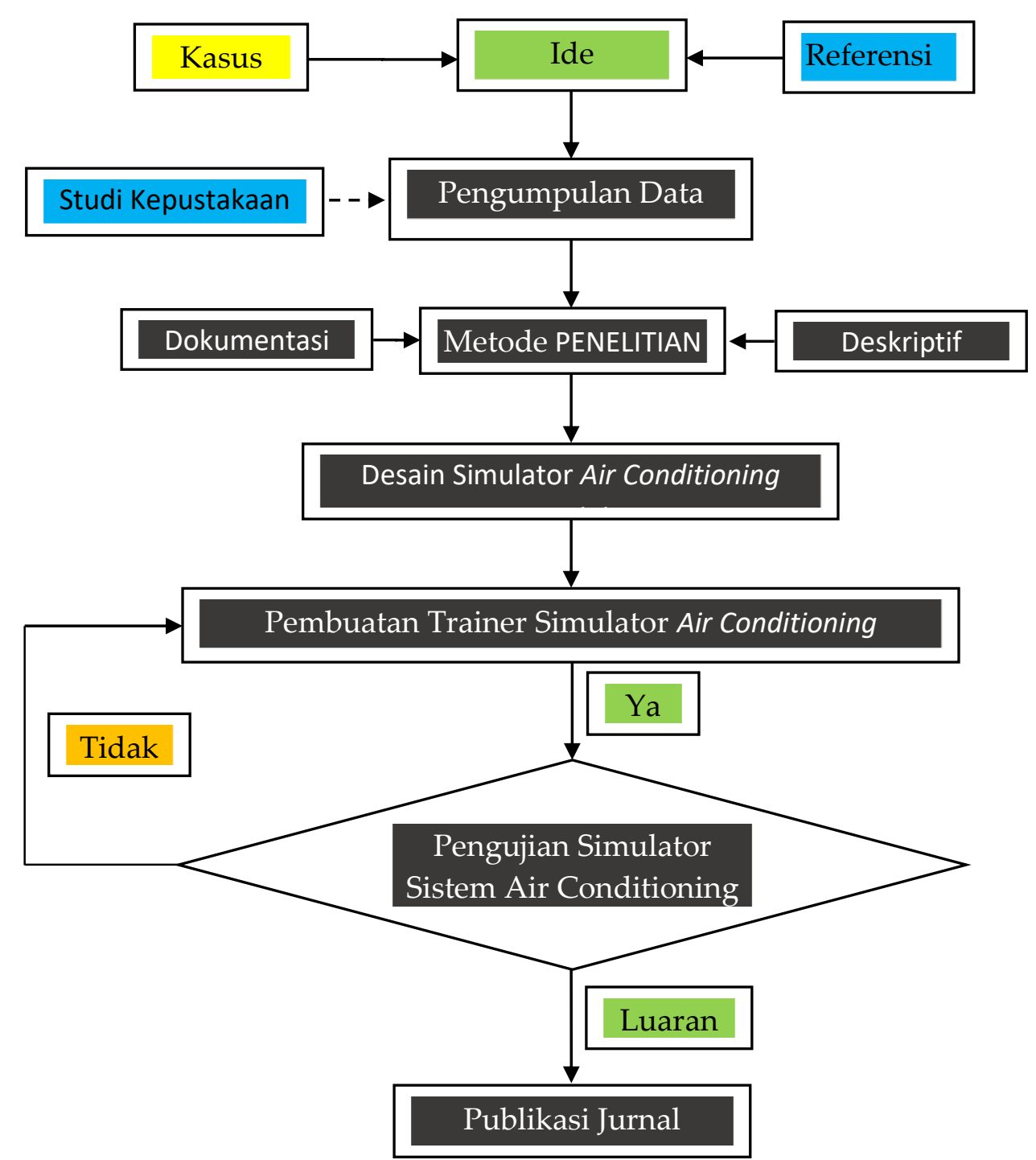

Gambar 3. Proses Pelaksanaan dan Target Luaran Penelitian 


\section{HASIL DAN PEMBAHASAN}

Hasil dan pembahasan dari pengujian sirkulasi pendingin pada trainer simulator Air Conditioning mobil adalah sebagai berikut:

\subsection{Hasil}

Hasil dari pembuatan dan pengujian sirkulasi pendingin pada Trainer Simulator Air Conditioning mobil disajikan pada Gambar 4.

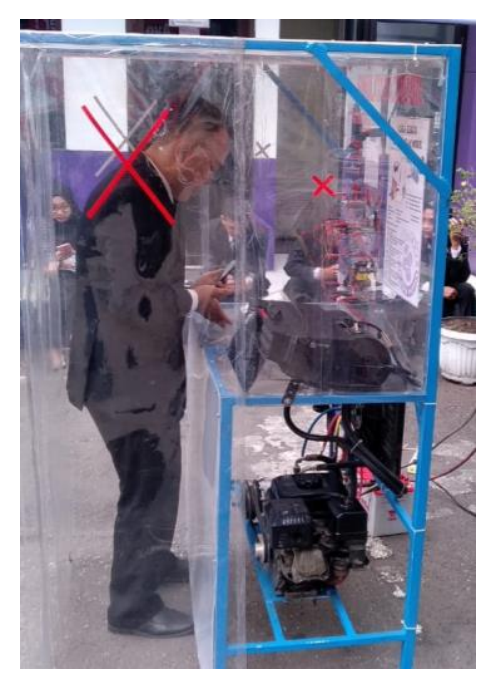

Gambar 4. Hasil Pembuatan dan Pengujian Sirkulasi Pendingin pada Trainer Simulator Air Conditioning

Dari hasil pengujian sirkulasi pendingin menggunakan termometer sebagai alat uji pada trainer simulator air conditioning mobil untuk mendeteksi suhu [10] disajikan pada Gambar 5.

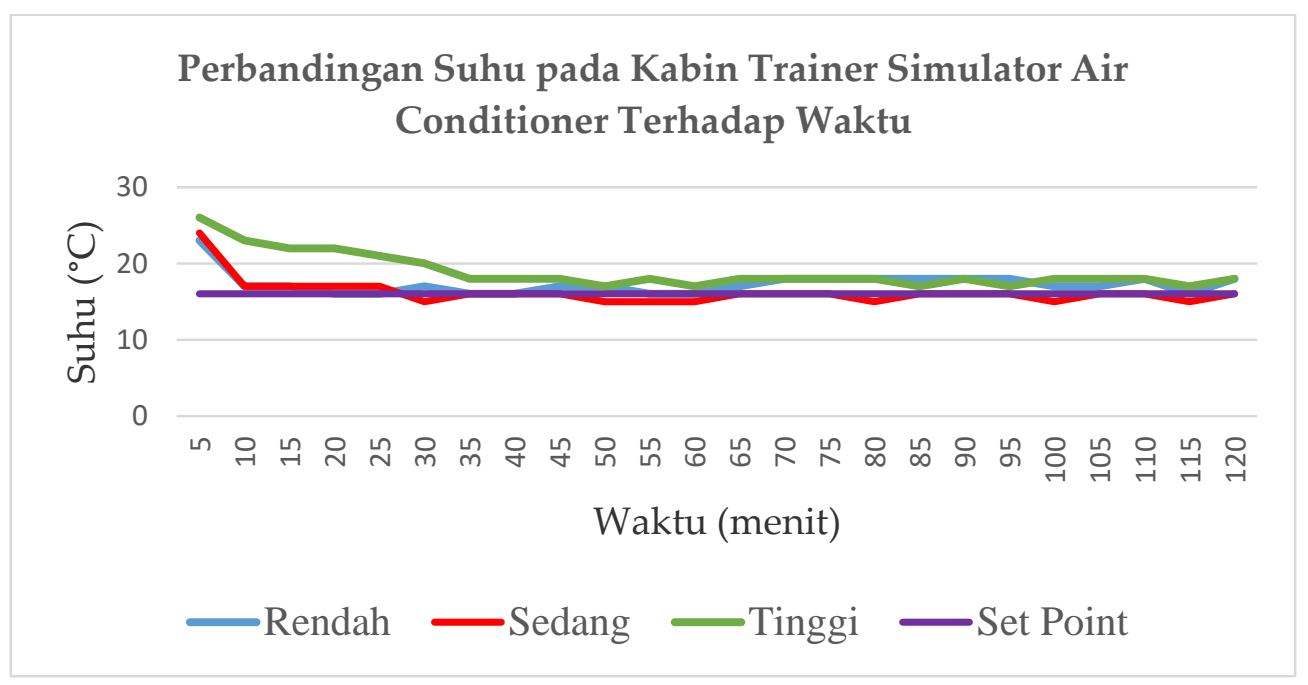

Gambar 5. Perbandingan Suhu Sirkulasi Pendingin Pada Trainer Simulator Air Conditioning

\subsection{Pembahasan}

Pembahasan hasil pengujian sirkulasi pendingin yang disajikan pada gambar 5 menunjukkan perbandingan suhu dengan menggunakan kecepatan blower tinggi, sedang dan 
rendah. Pada kecepatan putaran blower tinggi suhu kabin simulator air conditioner rata-rata $17^{\circ} \mathrm{C}$ pada menit ke-20. Pada kecepatan putaran blower sedang suhu kabin simulator air conditioner rata-rata $17^{\circ} \mathrm{C}$ pada menit ke-20. Sedangkan untuk kecepatan blower rendah ratarata suhu kabinnya $20^{\circ} \mathrm{C}$ pada menit ke-20.

Pembahasan pada hasil pembuatan trainer simulator air conditioning mobil ketika dilakukan pengujian pada sirkulasi pendingin secara keseluruhan komponen berfungsi dengan baik. Hal tersebut dapat memudahkan kepahaman mahasiswa dalam melakukan pengujian dengan trainer simulator air conditioning dalam ruangan mobil yang sesungguhnya. Ketika dilakukan pengujian trainer simulator air conditioning menunjukkan ada perbedaan suhu pada setiap kecepatan putaran blower. Jadi dapat disumpulkan bahwa adanya indikator suhu yang berubah sesuai dengan kecepatan blower, menunjukan media pembelajaran trainer simulator air conditioning mobil berfungsi normal dan efektif digunakan untuk praktikum pada mata kuliah sistem air conditioning mobil.

\section{KESIMPULAN}

Berdasarkan hasil pembuatan dan pengujian pada kabin sirkulasi pendingin pada trainer simulator air conditioning mobil dapat disimpulkan trainer dapat difungsikan dengan baik sebagai media pembelajaran yang efektif. Hal tersebut dapat meningkatkan pengetahuan dan kompetensi mahasiswa sehingga ketika melakukan praktikum dapat merasakan temperatur didalam kabin simulator air conditioning dan mengetahui hasil pengujianya.

\section{REFERENSI}

[1] J. P. Yadav and B. R. Singh, "Experimental Set up of Air Conditioning System in Automobile Using Exhaust Energy," SAMRIDDHI A J. Phys. Sci. Eng. Technol., vol. 5, no. 1, pp. 2010-2014, 2015, doi: 10.18090/samriddhi.v5i1.1520.

[2] A. Pathania and D. Mahto, "Recovery of Engine Waste Heat for Reutilization in Air Conditioning System in an Automobile: An Investigation," Glob. J. Res. Eng. Mech. Mech. Eng., vol. 12, no. 1, pp. 7-19, 2012, [Online]. Available: www.ijirse.com/wpcontent/upload/2016/02/492V.pdf\%5Cn.

[3] P. D. Dan, K. K. Kondensor, T. Suhu, and A. C. Mobil, “V10 n2,” no. March, pp. 193-198, 2019.

[4] D. U. Kim, H. Lee, S. G. Kim, J. H. Ahn, S. Y. Park, and J. O. Ka, “Spirosoma aerolatum sp. Nov., Isolated from a motor car air conditioning system," Int. J. Syst. Evol. Microbiol., vol. 65, no. 11, pp. 4003-4007, 2015, doi: 10.1099/ijsem.0.000528.

[5] B. K. Kanabar and B. M. Ramani, "Thermodynamic Analysis of Single Effect, Double Effect and Multi Effect LiBr / H2O Vapour Absorption Refrigeration Cycle," J. Refrig. Air 
Cond. Heat. Vent., vol. 4, no. 1, pp. 43-55, 2018, [Online]. Available: https://www.researchgate.net/publication/326146755_Journal_of_Refrigeration_Air_Con ditioning_Heating_and_Ventilation_Thermodynamic_Analysis_of_Single_Effect_Double _Effect_and_Multi_Effect_LiBrH_2_O_Vapour_Absorption_Refrigeration_Cycle.

[6] M. S. Gaga Putra Setiawan1,*, Oktavi Barkah Lukmana1, David Prayogo1, "Studi Eksperimental Pendingin Udara (Air Cooler) Dengan Thermo-Electric Pada Kabin Mobil," J. Tek. Mesin, vol. 11, no. 1, pp. 79-84, 2018.

[7] F. Sugara and Y. T. Mulya, "Pengaruh Kecepatan Putaran Blower Evaporator Terhadap," J. Teknol. Terap., vol. 4, no. September, 2018.

[8] U. N. S. Hidayat, M. Rifqi D3 Teknik Mesin, Fakultas Teknik, “REKAYASA TRAINER SISTEM AC MOBIL UNTUK MEMVARIASIKAN KAPASITAS Abstrak," Jrm, vol. 02, no. 2, pp. 46-51, 2015.

[9] B. Udara, "Prosiding Seminar Nasional Biotik 2014," pp. 288-293, 2014.

[10] H. A. E. W. O. N. JUNG, W. YOON, H. J. CHUNG, and Y. KIM, “PERFORMANCE CHARACTERISTICS OF A BYPASS TWO-CIRCUIT REFRIGERATION CYCLE DESIGNED FOR REFRIGERATORS," Int. J. Air-Conditioning Refrig., vol. 18, no. 02, pp. 141-147, Jun. 2010, doi: 10.1142/S2010132510000241. 